doi:10.1016/j.gca.2004.04.028

\title{
Geochemical test for branching decay of ${ }^{176} \mathrm{Lu}$
}

\author{
Y. Amelin* and W. J. Davis \\ Geological Survey of Canada, 601 Booth Street, Ottawa, Ontario, Canada
}

(Received October 16, 2003; accepted in revised form April 20, 2004)

\begin{abstract}
Two different groups of values for the ${ }^{176} \mathrm{Lu}$ decay constant have been determined by recent high-precision experiments. The $\lambda^{176} \mathrm{Lu}$ values of $1.86-1.87 \times 10^{-11} \mathrm{a}^{-1}$ were determined by age comparisons using terrestrial minerals of Proterozoic and late Archean age, whereas values of $\sim 1.94 \times 10^{-11} \mathrm{a}^{-1}$ were determined in age comparison studies of meteorites.

A possible branched decay of ${ }^{176} \mathrm{Lu}$ could be the cause of this discrepancy. The $\beta^{+}$decay of ${ }^{176} \mathrm{Lu}$ to ${ }^{176} \mathrm{Yb}$ was detected in the early studies of radioactivity of ${ }^{176} \mathrm{Lu}$, with reported values of $\lambda \beta^{+} /\left(\lambda \beta^{+}+\lambda \beta^{-}\right)$in the total ${ }^{176} \mathrm{Lu}$ ranging from less than 0.03 to 0.67 . If the $\beta^{+}$decay fraction is close to the upper limit of the reported values, it can explain the $4 \%-6 \%$ difference between the apparent $\lambda^{176} \mathrm{Lu}$ values.

To get a reliable estimate for the $\beta^{+}$decay of ${ }^{176} \mathrm{Lu}$, we have measured $\mathrm{Yb}$ isotopic composition in $2.7 \mathrm{Ga}$ zircons with $\mathrm{Lu} / \mathrm{Yb}_{\mathrm{N}}$ (chondrite-normalized) ratios of 1.40 and 1.45 , in $1.0 \mathrm{Ga}$ xenotime with $\mathrm{Lu} / \mathrm{Yb}_{\mathrm{N}}=1.23$, using $\mathrm{Yb}$ from the $28.4 \mathrm{Ma}$ Fish Canyon Tuff (FCT) zircon and titanite as the modern reference value. Multiple analyses yielded the following weighted mean values $( \pm 2 \sigma)$ for the ${ }^{176} \mathrm{Yb} /{ }^{174} \mathrm{Yb}$ ratio: 0.4022134 \pm 0.0000017 for the FCT zircon and titanite, $0.4022134 \pm 0.0000019$ for the $1.0 \mathrm{Ga}$ xenotime, and 0.4022124 \pm 0.0000033 for the $2.7 \mathrm{Ga}$ zircons. These data yield $\lambda \beta^{+} /\left(\lambda \beta^{+}+\lambda \beta^{-}\right)=-0.005 \pm 0.015(2 \sigma)$ and establish an upper limit of $0.9 \%$ of total decays for the $\beta^{+}$decay branch. Branching decay can therefore be eliminated as the cause of the discrepancy in ${ }^{176} \mathrm{Lu}$ decay constant estimates. We discuss other possible causes of the $\lambda^{176} \mathrm{Lu}$ terrestrial vs. meteorite discrepancy. Copyright $\odot 2005$ Elsevier Ltd
\end{abstract}

\section{INTRODUCTION}

\subsection{The $\lambda^{176} \mathrm{Lu}$ Dilemma}

Accurate isotopic age determinations, and the use of radiogenic isotopes to decipher the evolution of the sources of ancient rocks, are impossible without knowing precise and accurate values of decay constants. Development of highly efficient and precise MC-ICPMS techniques for Hf isotope analysis (Blichert-Toft et al., 1997) makes the Lu-Hf method one of the most potent chronometers and isotopic tracers. However, the large uncertainty in the ${ }^{176} \mathrm{Lu}$ decay constant severely limits its usefulness. Patchett and Tatsumoto (1980) and Patchett et al. (1981), originally calculated a $\lambda^{176} \mathrm{Lu}$ value of $1.94 \pm 0.07\left(\times 10^{-11} \mathrm{a}^{-1}\right.$, understood throughout $)$ based on age comparisons for differentiated meteorites. This empirically-derived value was substantiated by a value of $1.93 \pm 0.03$ measured by Sguigna et al. (1982) from $\gamma-\gamma$ coincidence counting. These values were widely adopted within the geological community until later counting (Nir-el and Lavi, 1998) and age comparison (Scherer et al., 2001) studies yielded more precise, but distinctly lower $\lambda^{176} \mathrm{Lu}$ values of $1.86 \pm 0.01$ and $1.865 \pm$ 0.015 , respectively. Although this lower value gained increasing acceptance in the geochemical community, the controversy has been reawakened because of recently reported $\lambda^{176} \mathrm{Lu}$ values spanning 1.93-1.98, obtained from meteorite isochrons (Blichert-Toft et al., 2002; Bizzarro et al., 2003a).

Substantial effort has been recently committed to solving this $\lambda^{176} \mathrm{Lu}$ dilemma (Fig. 1) but it is still unresolved. New $\gamma$-counting studies (Grinyer et al., 2003; Nir-El and Haquin, 2003) show the same wide scatter of the apparent decay constant

* Author to whom correspondence should be addressed (yamelin@ nrcan.gc.ca). values as the earlier studies, which indicates that major unresolved analytical problems still exist in $\gamma$-counting techniques, as pointed out by Begemann et al. (2001) and Blichert-Toft et al. (2002). New age comparison studies with improved analytical precision were performed by several groups using both terrestrial minerals and meteorites (Bizzarro et al., 2003b; Scherer et al., 2002, 2003; Söderlund et al., 2004; Patchett et al., 2004). Meteorite age comparisons have been done using both chondrites (Bizzarro et al., 2003a,b; Patchett et al., 2004), and differentiated meteorites: eucrites (Blichert-Toft et al., 2002; Scherer et al., 2002, 2003) and angrites (Blichert-Toft et al., 2004, Bizzarro, personal communication, 2003). Terrestrial age comparisons now include a variety of minerals with a wide range of ages between 0.9-2.8 Ga (Scherer et al., 2003; Söderlund et al., 2004). Collectively, these studies produced internally consistent but discrepant $\lambda^{176} \mathrm{Lu}$ values between terrestrial minerals and meteorites (Scherer et al., 2002; Bizzarro et al., 2003a). As some terrestrial and meteoritic age comparisons were performed in the same labs using identical techniques and spike calibrations, an interlaboratory analytical bias cannot be the source of the discrepancy (Scherer et al., 2002). Furthermore, all these studies rely on extensive, high-quality ${ }^{207} \mathrm{~Pb} /$ ${ }^{206} \mathrm{~Pb}$ and $\mathrm{U}-\mathrm{Pb}$ data as the primary age reference, so the meteorite-terrestrial mineral discrepancy cannot be explained by a bias in the primary age references.

The reason for the meteorite vs. terrestrial mineral $\lambda^{176} \mathrm{Lu}$ discrepancy is currently unknown. To reliably constrain the ${ }^{176} \mathrm{Lu}$ decay rate, we need to evaluate and eliminate all factors that may influence the apparent $\lambda^{176} \mathrm{Lu}$ value determined from age comparisons. One of the possible causes of the apparent variation of $\lambda^{176} \mathrm{Lu}$ with the age of the analyzed material is branched decay of ${ }^{176} \mathrm{Lu}$. If a considerable portion of ${ }^{176} \mathrm{Lu}$ atoms decay by electron capture or positron emission (collec- 
tively referred to as $\beta^{+}$decay), then the apparent decay constant of the $\beta^{-}$branch $\lambda\left(\beta^{-}\right)$will increase with the age of the sample used for age comparison (Fig. 2). Since meteorites are 2-5 times older than the terrestrial minerals used in the age comparison studies of the ${ }^{176} \mathrm{Lu}$ decay rate, the existence of $\beta^{+}$ decay branch may explain the observed discrepancy between the meteorite and terrestrial data. Here we evaluate the $\beta^{+}$ decay of ${ }^{176} \mathrm{Lu}$ by measuring radiogenic ${ }^{176} \mathrm{Yb}$ in ancient minerals with elevated $\mathrm{Lu} / \mathrm{Yb}$ ratio.

\subsection{Previous Studies of Branched Decay of ${ }^{176} \mathrm{Lu}$}

${ }^{176} \mathrm{Lu}$ is an odd-odd nuclide and a middle member of a triplet of adjacent isobars. Three other naturally occurring long-lived radioactive nuclides in a similar position, ${ }^{40} \mathrm{~K},{ }^{50} \mathrm{~V}$ and ${ }^{138} \mathrm{La}$, experience both $\beta^{+}$and $\beta^{-}$decay, with the portion of $\beta^{+}$ decay between $66 \%-89 \%$ of the total number of $\beta$ decays (Audi et al., 1997). The fifth middle member of a natural isobar triplet, ${ }^{180} \mathrm{Ta}$, is stable. Comparison with ${ }^{40} \mathrm{~K},{ }^{50} \mathrm{~V}$ and ${ }^{138} \mathrm{La}$ suggests that substantial $\beta^{+}$radioactivity of ${ }^{176} \mathrm{Lu}$ must be considered.

A substantial $\beta^{+}$decay branch was suggested in early studies of ${ }^{176} \mathrm{Lu}$ radioactivity. Flammersfeld (1947) reported a

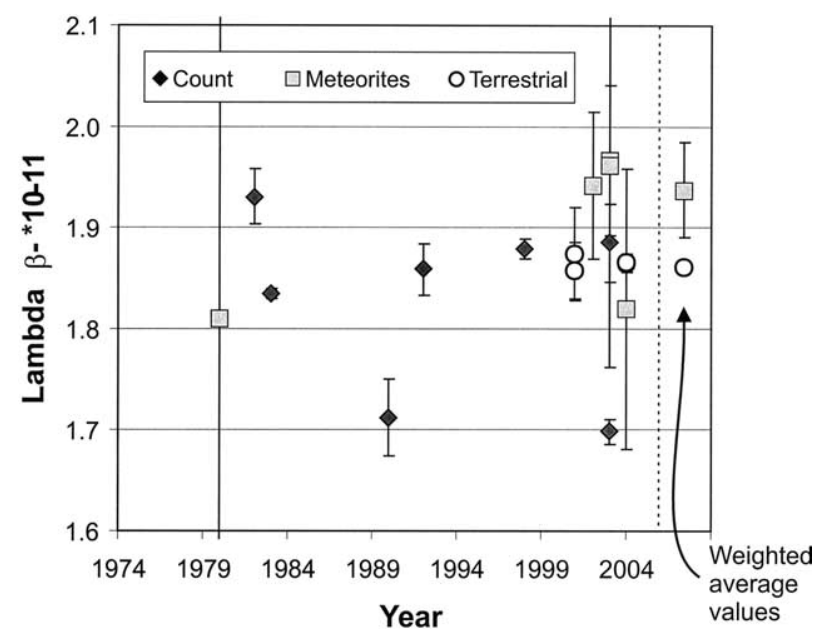

Fig. 1. Summary of published values of $\lambda^{176} \mathrm{Lu}$ determined during last $25 \mathrm{yr}$ using $\gamma$-counting (black diamonds), and age comparison against $\mathrm{U}-\mathrm{Pb}$ on meteorites (gray squares) and on terrestrial rocks (white circles). The sources of data: $\gamma$-counting - Sguigna et al. (1982); Sato et al. (1983); Gehrke et al. (1990); Dalmasso et al. (1992), Nir-el and Lavi (1998), Grinyer et al. (2003), Nir-El and Haquin (2003); meteorite age comparisons-Patchett and Tatsumoto (1980), BlichertToft et al. (2002), Bizzarro et al. (2003)a; terrestrial rock age comparisons-Scherer et al. (2001); Söderlund et al. (2004). Since various isochron regression methods were used in the age comparison $\lambda^{176} \mathrm{Lu}$ determinations, we have recalculated all $\mathrm{Lu}-\mathrm{Hf}$ isochrons using Isoplot Ex 2.49 (Ludwig, 2001) program to assure compatibility of results. The isochrons were regressed using the default settings of the Isoplot (model 3 is invoked if the probability of fit is lower than 0.15 ). The uncertainties in Lu/Hf and $\mathrm{Hf}$ isotopic ratios, sorting of the data (inclusion or exclusion of certain analyses), and age references in terrestrial age comparison studies, are as in the original publications. For the chondrites and basaltic eucrites, we assumed the age of $4.56 \pm$ $0.01 \mathrm{Ga}$. The chondrite and eucrite analyses from Bizzarro et al. (2003)a were regressed separately. Cumulate eucrites are not included in this compilation because of uncertainty in their age. The details of the isochron recalculations are given in Table EA-1.

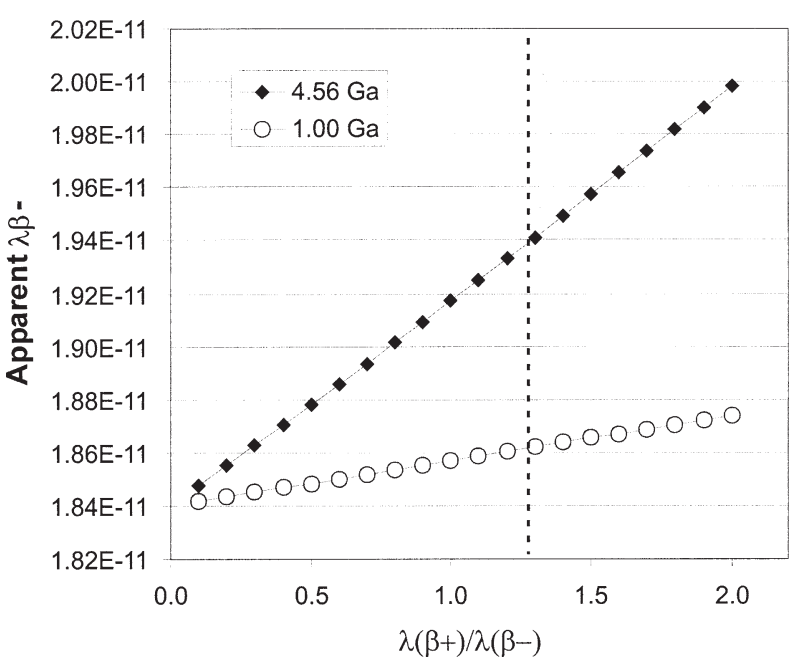

Fig. 2. Dependence of apparent $\lambda\left(\beta^{-}\right)$of ${ }^{176} \mathrm{Lu}$, determined in age comparison studies, on the branching ratio $\lambda\left(\beta^{+}\right) / \lambda(\beta-)$ and the age of the sample. The $\lambda^{176} \mathrm{Lu}$ values observed in age comparison studies of meteorites (ca. $4.56 \mathrm{Ga}$ ) and terrestrial rocks (mostly ca. $1.0 \mathrm{Ga}$ ) can be reproduced at the branching ratio $\sim 1.3$ (a value marked by a vertical dashed line).

decay scheme for naturally radioactive lutetium (also known in those days as cassiopeium) in which both $\beta^{+}$and $\beta^{-}$decays exist with the ratio $\beta^{+} / \beta^{-}=2$. Subsequent decay counting studies, which specifically searched for branched decay, determined much lower ratios of $\beta^{+} / \beta^{-}=0.03 \pm 0.01$ (Dixon et al., 1954), $\beta^{+} / \beta^{-}<0.1$ (Arnold, 1954), or did not detect $\beta^{+}$ decay at all (Arnold and Sugihara, 1953; ${ }^{1}$ Glover and Watt, 1957). In numerous subsequent $\gamma$-counting studies, some of which are listed in the caption of Figure 1 and in the electronic annex Table EA-1, ${ }^{176} \mathrm{Lu}$ was considered a nuclide that does not experience branched decay.

\subsection{A Simple Geochemical Test for Branched Decay of ${ }^{176} \mathrm{Lu}$}

Significant $\beta^{+}$decay of ${ }^{176} \mathrm{Lu}$ (either electron capture or positron emission), will result in accumulation of radiogenic ${ }^{176} \mathrm{Yb}$. The magnitude of the increase in ${ }^{176} \mathrm{Yb} /{ }^{174} \mathrm{Yb}$ ratio due to accumulation of radiogenic ${ }^{176} \mathrm{Yb}$ in a mineral depends on the age of the mineral, the $\mathrm{Lu} / \mathrm{Yb}$ ratio, and the decay constant $\lambda\left(\beta^{+}\right)$. Therefore, $\lambda\left(\beta^{+}\right)$can be calculated, if the age, $\mathrm{Lu} / \mathrm{Yb}$, and ${ }^{176} \mathrm{Yb} /{ }^{174} \mathrm{Yb}$ ratios of a mineral are known with sufficient precision and accuracy.

The potential magnitude of this effect in ${ }^{176} \mathrm{Yb} /{ }^{174} \mathrm{Yb}$ is illustrated in Figure 3. In a mineral of late Archean age of $2.7 \mathrm{Ga}$, with $\mathrm{Lu} / \mathrm{Yb}$ ratio twice the chondritic value $(0.1536$; Evensen et al., 1978; Anders and Grevesse, 1989), as little as $1 \% \beta^{+}$decay $\left(\beta^{+} / \beta^{-}=0.01\right)$ would produce a measurable radiogenic ingrowth of $0.0016 \%$. The geochemical test for

\footnotetext{
${ }^{1}$ The limit on the electron-capture decay branches of ${ }^{176} \mathrm{Lu}$, similar to our estimate, has been recently obtained using modern $\gamma$-ray counting technique (E. B. Norman, E. Browne, I. D. Goldman, P. R. Renne (2004), Improved limit on the electron capture decay branch of ${ }^{176} \mathrm{Lu}$. Applied Radiation and Isotopes 60, 767-770).
} 


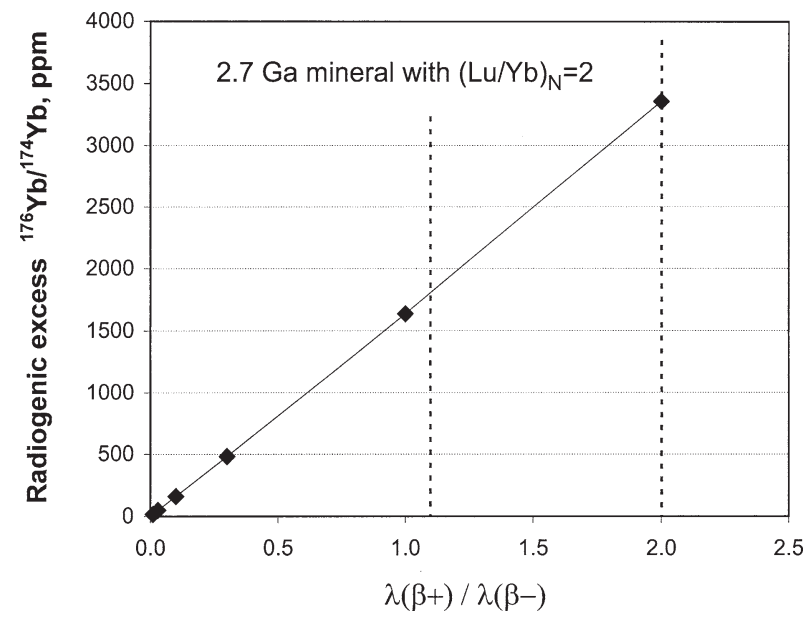

Fig. 3. Radiogenic growth of ${ }^{176} \mathrm{Yb}$ (expressed as a deviation of ${ }^{176} \mathrm{Yb} /{ }^{174} \mathrm{Yb}$ from chondritic value) as a function of branching ratio. The model assumes the age of the mineral of $2.7 \mathrm{Ga}$, and the $\mathrm{Lu} / \mathrm{Yb}$ ratio of 0.3072 , twice as high as in chondrites.

branched decay of ${ }^{176} \mathrm{Lu}$ therefore may be at least as sensitive as $\gamma$-counting.

Precise determination of $\lambda\left(\beta^{+}\right)$requires analysis of older minerals with high $\mathrm{Lu} / \mathrm{Yb}$ ratios and closed geochemical systems. Natural minerals with elevated $\mathrm{Lu} / \mathrm{Yb}$ are rare (e.g., McCulloch et al., 1976). Some minerals, for example xenotime and gadolinite, are highly enriched in heavy REE compared to light REE, and therefore may have relatively high $\mathrm{Lu} / \mathrm{Yb}$. These minerals also have very high $\mathrm{Lu} / \mathrm{Hf}$ ratio, and were successfully used in age comparison determinations of $\lambda\left(\beta^{-}\right)$ of ${ }^{176} \mathrm{Lu}$ (Scherer et al., 2001). Minerals of tetravalent metals, e.g., zircon, are also known to have elevated ratios of heavy REE to light REE. Both xenotime and zircon can be precisely dated using the $\mathrm{U}-\mathrm{Pb}$ method.

In this study, we have determined the $\mathrm{Lu} / \mathrm{Yb}$ ratio and $\mathrm{Yb}$ isotopic composition in three Mesoproterozoic xenotime samples and two Neoarchean zircon samples. As a reference with modern average $\mathrm{Yb}$ isotopic composition, we used zircon and titanite from $28 \mathrm{Ma}$ (Schmitz and Bowring, 2001) Fish Canyon Tuff.

\section{RESULTS}

Analytical procedures are described in the electronic annex EA-2. Sample descriptions for the individual minerals are provided in the publications cited below.

\subsection{U-Pb Geochronology}

$\mathrm{U}-\mathrm{Pb}$ data for the zircon samples are presented in Table EA-3. An age of $2696 \pm 2$ Ma for sample Z6970 from the La
Reine pluton in the Abitibi subprovince, Canada was reported by Davis et al., 2000. The data were collected at the GEOTOP laboratory, Université du Quebec à Montreal. Thirteen additional analyses carried out at the GSC laboratory yield a weighted mean ${ }^{207} \mathrm{~Pb} /{ }^{206} \mathrm{~Pb}$ age of $2697 \pm 1 \mathrm{Ma}$ $(\mathrm{MSWD}=2.1)$, within error of the published age of $2696 \pm$ $2 \mathrm{Ma}$. The data include 10 analyses of aliquots from a single solution prepared from $193 \mu \mathrm{g}$ of zircon, and two individual multi-grain analyses of abraded zircon. Results for zircon sample Z4510 were initially reported in Davis and Peterson (1998). These data along with two new analyses are presented in Table EA-3. Although one analysis yielded imprecise $\mathrm{Pb} / \mathrm{U}$ ratios due to a poor uranium analyses, the five analyses have a weighted mean ${ }^{207} \mathrm{~Pb} /{ }^{206} \mathrm{~Pb}$ age of $2700.0 \pm$ 1.4 Ma (MSWD = 2.1).

Ages and analytical data for the three xenotime samples, initially tested as possible SHRIMP ion probe standards are presented in Stern and Rayner (2003). A summary of the U-Pb ages is presented in Table 1 .

\subsection{Lu/Yb Ratios}

The $\mathrm{Lu}$ and $\mathrm{Yb}$ concentrations and $\mathrm{Lu} / \mathrm{Yb}$ ratios are reported in Table EA-4. The samples were analyzed in two analytical sessions using different standards and measurement sequences. Three aliquots were analyzed from some samples. Reproducibility estimated from these replicate measurements is between $0.14-0.98 \%$ (Relative Standard Deviation, RSD) with the exception of the whole rock 120 (a granitoid with low concentration of HREE), where the reproducibility is poorer due to excessive dilution, and hence low count rates during the second analytical session. Since the count rates were much higher for all the mineral analyses, we estimate the reproducibility of the $\mathrm{Lu} / \mathrm{Yb}$ ratio measurement at 2\% (2 RSD).

The accuracy of $\mathrm{Lu} / \mathrm{Yb}$ ratios is evaluated from measurements of the USGS standard rock BCR-1. The Lu and $\mathrm{Yb}$ concentrations determined in this study are in close agreement (concentrations within 5\% and the $\mathrm{Yb} / \mathrm{Lu}$ ratio within $1 \%$ ) with recent ICP-MS studies (Makishima and Nakamura, 1997; Robinson et al., 1999), and earlier data (Govindaraju, 1994). The agreement of $\mathrm{Yb}$ concentrations calculated from different $\mathrm{Yb}$ isotopes $(171,172,173$ and 174) is also within $2 \%$ for most samples. From these data, we conclude that our $\mathrm{Lu} / \mathrm{Yb}$ ratio measurements are precise and accurate within $2 \%$. This error does not significantly limit the precise determination of the $\lambda\left(\beta^{+}\right)$of ${ }^{176} \mathrm{Lu}$.

Separate digestions of mineral fractions picked from the same sample may give more scattered results than the aliquots if the mineral is heterogeneous. The difference between $\mathrm{Lu} / \mathrm{Yb}$ determined from separate digestions was less than $8 \%$.

All three whole rock samples and one of the xenotime

Table 1. Summary of mineral ages.

\begin{tabular}{lclcll}
\hline \multicolumn{1}{c}{ Sample } & GSC lab no. & Mineral & Age & Error & \multicolumn{1}{c}{ Reference } \\
\hline La Reine & z6970 & Zircon & 2697 & \pm 1.0 & Davis et al. (2000) \\
PHA-96-395 & z4510 & Zircon & 2700 & \pm 1.4 & Davis and Peterson (1998) \\
z6413 & z6413 & Xenotime & 996.7 & \pm 0.8 & Stern and Rayner (2003) \\
z6410 & z6410 & Xenotime & 901 & $+3 /-2$ & Stern and Rayner (2003) \\
z6409 & z6409 & Xenotime & 1020 & \pm 2.0 & Stern and Rayner (2003) \\
\hline
\end{tabular}




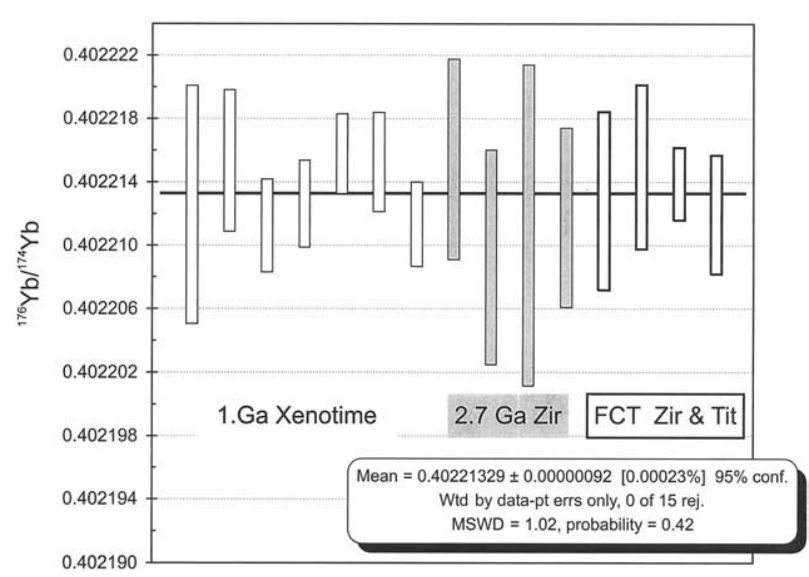

Fig. 4. Normalized and corrected for Lu interference ${ }^{176} \mathrm{Yb} /{ }^{174} \mathrm{Yb}$ ratios measured in xenotime, zircon and titanite.

samples have $\mathrm{Lu} / \mathrm{Yb}$ within $3 \%$ of the chondritic value. The two other xenotimes have chondrite-normalized $\mathrm{Lu} / \mathrm{Yb}$ ratios of $\sim 1.10$ and 1.22 . The $\mathrm{Lu} / \mathrm{Yb}$ ratios in all the zircons are substantially higher, between 1.40-1.45. The titanite has a $\mathrm{Lu} / \mathrm{Yb}$ ratio $\sim 20 \%$ lower than chondritic.

\subsection{Yb Isotopic Compositions}

The $\mathrm{Yb}$ isotopic ratios and their weighted mean values are reported in Table EA-5. The whole rock analyses are much less precise (by about an order of magnitude) than the mineral analyses, due to smaller $\mathrm{Yb}$ loads and smaller ion beams. These analyses are not precise enough for the $\lambda\left(\beta^{+}\right)$determination, and are not further considered. The nonradiogenic isotopic ratios ${ }^{171} \mathrm{Yb} /{ }^{174} \mathrm{Yb}$ and ${ }^{173} \mathrm{Yb} /{ }^{174} \mathrm{Yb}$ do not show systematic variations between samples, with the exception of slightly lower (by $20 \mathrm{ppm}$ ) ${ }^{171} \mathrm{Yb} /{ }^{174} \mathrm{Yb}$ in the Spex standard than the minerals. The reason for this discrepancy is unknown, but it is not caused by an imperfect fractionation correction, because measured ${ }^{172} \mathrm{Yb} /{ }^{174} \mathrm{Yb}$ ratios in the Spex standard measurements are within the same range as the mineral values.

The ${ }^{176} \mathrm{Yb} /{ }^{174} \mathrm{Yb}$ ratios in the minerals, normalized and corrected for Lu interference, are shown in Figure 4. The ratios measured in all 14 mineral fractions ( $\mathrm{Yb}$ analyses from fractions of xenotime 6410 were replicated) are reproducible within errors of individual analyses. The $95 \%$ confidence error of $2.9 \mathrm{ppm}$ for the weighted mean of 15 analyses corresponds to reproducibility of $11 \mathrm{ppm}$.

\section{DISCUSSION}

\subsection{Magnitude of Branching Decay of ${ }^{176} \mathrm{Lu}$}

From the uniformity of $\mathrm{Yb}$ isotopic composition in minerals with large variations in age and $\mathrm{Lu} / \mathrm{Yb}$ ratio, it follows that the $\lambda\left(\beta^{+}\right)$of ${ }^{176} \mathrm{Lu}$ is indistinguishable from zero within error limits. It is possible, however, to estimate the upper limit of $\lambda\left(\beta^{+}\right)$. This can be done by comparison of the error limits of $\mathrm{Yb}$ isotopic composition in the chondritic uniform reservoir, and in the oldest mineral with highest $\mathrm{Lu} / \mathrm{Yb}$ that is most likely to have the largest excess of radiogenic $\mathrm{Yb}$. Rare earth data for whole rocks (Rudnick and Fountain,
1995; Taylor and McLennan, 1995) indicate little variability of $\mathrm{Lu} / \mathrm{Yb}_{\mathrm{N}} \approx 1$ between all common rock types, with the possible exception of highly depleted peridotites (e.g., Prinzhofer and Allègre, 1985). Therefore, most crustal rocks are expected to have a $\mathrm{Yb}$ isotopic composition indistinguishable from chondritic. In this study, we use the $\mathrm{Yb}$ isotopic composition in zircon and titanite from the Fish Canyon Tuff as a chondritic proxy. The $\mathrm{Lu} / \mathrm{Yb}$ ratios in representative rocks of the Fish Canyon igneous suite, exhibit little variation and are indistinguishable from the chondritic value (the average chondrite-normalized $\mathrm{Lu} / \mathrm{Yb}$ ratio is $1.00 \pm 0.03$ (1 SD), based on the data of Bachmann et al., 2002, see Table EA-6). This suggests that the protolith of the Fish Canyon tuff had chondritic $\mathrm{Lu} / \mathrm{Yb}$ ratio, and therefore chondritic $\mathrm{Yb}$ isotopic composition. The $\mathrm{Yb}$ isotopic composition of the minerals that crystallized recently from a rock with unfractionated $\mathrm{Lu} / \mathrm{Yb}$ will also be chondritic, irrespective of the $\mathrm{Lu} / \mathrm{Yb}$ ratio in the mineral. It should be noted that the Spex standard, or any other reagent $\mathrm{Yb}$ cannot be used as a chondritic proxy without identifying its source mineral.

The $1.0 \mathrm{Ga}$ xenotimes and $2.7 \mathrm{Ga}$ zircons can serve as monitors of "radiogenic" $\mathrm{Yb}$ ingrowth. The zircon are expected to contain five times the radiogenic $\mathrm{Yb}$ component relative to the xenotime, owing to their older age and higher $\mathrm{Lu} / \mathrm{Yb}$ ration. Despite the fact that the average ${ }^{176} \mathrm{Yb} /{ }^{174} \mathrm{Yb}$ measured in the zircons is 1.7 times less precise than in the xenotimes, the zircon data provide the most precise estimate for the $\lambda\left(\beta^{+}\right)$. Moreover, the similar ages and $\mathrm{Lu} / \mathrm{Yb}$ ratios of the two Neoachean zircons allow $\mathrm{Yb}$ analyses to be averaged, for better precision. In the following discussion, we consider only the FCT mineral ${ }^{176} \mathrm{Yb} /{ }^{174} \mathrm{Yb}$ average, and the average $\mathrm{Lu} / \mathrm{Yb}$ and ${ }^{176} \mathrm{Yb} /{ }^{174} \mathrm{Yb}$ of the Archean zircons.

The difference between the average ${ }^{176} \mathrm{Yb} /{ }^{174} \mathrm{Yb}$ for the FCT and the Archean zircons is $-0.0000013 \pm 0.0000037$ (95\% confidence interval calculated as a quadratic sum of individual confidence intervals; Table 2). Therefore, the maximum possible excess in the zircon ${ }^{176} \mathrm{Yb} /{ }^{174} \mathrm{Yb}$ is 0.0000024 at $95 \%$ confidence level (the lower line in Table $2)$. The models of radiogenic growth of ${ }^{176} \mathrm{Yb}$ are presented in Table 3. These data yield $\lambda\left(\beta^{+}\right) /\left(\lambda \beta^{+}+\lambda \beta^{-}\right)=-0.005$ $\pm 0.015(2 \sigma)$ and establish an upper limit of $\lambda\left(\beta^{+}\right)=1.71$ $\times 10^{-13}$. No more than $0.9 \%$ of the total number of decays of ${ }^{176} \mathrm{Lu}$ can possibly belong to the $\beta^{+}$decay branch. Our data confirm the findings of the early $\gamma$-counting studies (Arnold and Sugihara, 1953; Arnold, 1954; Dixon et al., 1954; Glover and Watt, 1957) that the $\beta^{+}$decay of ${ }^{176} \mathrm{Lu}$ is extremely slow or nonexistent, and set a more stringent upper limit on the $\beta^{+}$fraction in the total decays of ${ }^{176} \mathrm{Lu}$.

The estimated maximum value for the $\beta^{+}$decay branch can be compared to the value necessary to produce the observed difference of apparent $\lambda\left(\beta^{-}\right)$obtained from meteorites and terrestrial rocks. To reproduce the apparent $\lambda\left(\beta^{-}\right) \approx 1.86 \times 10^{-11}$ for $1 \mathrm{Ga}$ rocks and $\lambda\left(\beta^{-}\right) \approx 1.94 \times$ $10^{-11}$ for $4.56 \mathrm{Ga}$ meteorites, we need a true value of $\lambda\left(\beta^{-}\right)$ $=1.84 \times 10^{-11}$ and $\lambda\left(\beta^{+}\right)=2.39 \times 10^{-11}$. The latter value is 140 times higher than our upper limit for $\lambda\left(\beta^{+}\right)$. Branching decay can therefore be eliminated as the cause of the discrepancy in ${ }^{176} \mathrm{Lu}$ decay constant estimates. 
Table 2. Summary of $176 \mathrm{Yb} / 174 \mathrm{Yb}$ ratios.

\begin{tabular}{|c|c|c|c|c|c|}
\hline Sample & $\begin{array}{r}{ }^{176} \mathrm{Yb} /{ }^{174} \mathrm{Yb} \\
\text { norm, corr }\end{array}$ & Error $^{b}$ & Error\% ${ }^{\mathrm{b}}$ & $\operatorname{Min}^{c}$ & $\operatorname{Max}^{\mathrm{d}}$ \\
\hline Spex average & 0.4022108 & 0.0000023 & 0.00057 & & \\
\hline Xenotime average & 0.4022134 & 0.0000019 & 0.00047 & & \\
\hline 2.7 Ga Zir average & 0.4022121 & 0.0000033 & 0.00082 & & \\
\hline FCT average & 0.4022134 & 0.0000017 & 0.00042 & & \\
\hline Xenotime-FCT & 0.0000000 & 0.0000025 & 0.00063 & -0.0000025 & 0.0000025 \\
\hline $2.7 \mathrm{Ga}$ Zir-FCT & -0.0000013 & 0.0000037 & 0.00092 & -0.0000050 & 0.0000024 \\
\hline
\end{tabular}

\subsection{Other Possible Causes of the ${ }^{176} \mathrm{Lu}$ Decay Dilemma}

The discrepancy between "terrestrial" and "meteorite" apparent values of $\lambda^{176} \mathrm{Lu}$ can be explained if: 1) the $\mathrm{Lu}-\mathrm{Hf}$ isochrons used in age comparisons have initial slope (negative for terrestrial samples, or positive for meteorites); 2) the U-Pb reference ages are incorrect; or 3) the Lu- $\mathrm{Hf}$ and $\mathrm{U}-\mathrm{Pb}$ systems closed at different times. Bizzarro et al. (2003a) suggested that terrestrial age comparison determinations by Scherer et al. (2001) might have been affected by poorly-known closure temperature estimates for minerals that have the highest $\mathrm{Lu} / \mathrm{Hf}$ ratios, and hence control the slope of Lu-Hf isochrons: gadolinite, xenotime and apatite. Late closure of the Lu-Hf system in these minerals compared to U-Pb systems would be equivalent to having a negative slope of Lu-Hf internal isochrons at the time of $\mathrm{U}-\mathrm{Pb}$ closure. However, good agreement between apparent decay constant values determined using a variety of minerals from different geological settings indicate that the age comparison determinations of Scherer et al. (2001) were not noticeably affected by slow cooling. In addition, possible problems related to slow cooling were addressed and excluded in

Table 3. Radiogenic growth of ${ }^{176} \mathrm{Yb}$.

\begin{tabular}{|c|c|c|c|}
\hline$\lambda \beta^{-} \mathrm{y}-1$ & $\lambda \beta^{+} / \lambda \beta^{-}$ & $\lambda \beta^{+} \mathrm{y}-1$ & $\begin{array}{l}{ }^{176} \mathrm{Yb} /{ }^{174} \mathrm{Yb} \\
\text { radiogenic }\end{array}$ \\
\hline \multicolumn{4}{|c|}{ Model } \\
\hline $1.90 \mathrm{E}-11$ & 0.01 & $1.90 \mathrm{E}-13$ & 0.0000027 \\
\hline $1.90 \mathrm{E}-11$ & 0.03 & $5.70 \mathrm{E}-13$ & 0.0000081 \\
\hline $1.90 \mathrm{E}-11$ & 0.10 & $1.90 \mathrm{E}-12$ & 0.0000271 \\
\hline $1.90 \mathrm{E}-11$ & 0.30 & $5.70 \mathrm{E}-12$ & 0.0000818 \\
\hline $1.90 \mathrm{E}-11$ & 1.00 & $1.90 \mathrm{E}-11$ & 0.0002776 \\
\hline
\end{tabular}

Average measured value

$\begin{array}{llll}1.90 \mathrm{E}-11 & -0.005 & -9.27 \mathrm{E}-14 & -0.0000013\end{array}$

Upper limit of the measured value

$\begin{array}{llll}1.90 \mathrm{E}-11 & 0.009 & 1.71 \mathrm{E}-13 & 0.0000024\end{array}$

\footnotetext{
${ }^{a}$ Radiogenic growth of ${ }^{176} \mathrm{Yb} /{ }^{174} \mathrm{Yb}$ in a mineral due to $\beta+$ decay of ${ }^{176} \mathrm{Lu}$, in excess of radiogenic growth in chondritic unifirm reservoir. The following parameters are used in the ingrowth calculations: chondritic $\mathrm{Lu} / \mathrm{Hf}=0.1536 ; \mathrm{Lu} / \mathrm{Hf}$ in the studied mineral 0.2184 (the average of two studied $2.7 \mathrm{Ga}$ zircons); the age of the mineral $-2.7 \mathrm{Ga}$.
}

the Lu-Hf and U-Pb age comparison study of Proterozoic dolerites by Söderlund et al. (2004). The $\lambda^{176} \mathrm{Lu}$ values obtained from these quickly cooled and very well preserved mafic intrusions strongly support the values of Scherer et al. (2001, 2002), and argue against the bias in the "terrestrial" values being caused by slow cooling.

Meteorite data can also be potentially biased by a number of factors. The meteorites analyzed for age comparison determinations of $\lambda^{176} \mathrm{Lu}$ are, strictly speaking, not perfect objects for these studies. Chondrites are mixtures of components of variable ages: chondrules, refractory inclusions, matrix, and metamorphic minerals. Their timing of accretion is bracketed between the age of chondrules (Amelin et al., 2002), and the age of metamorphic minerals, e.g., phosphates (Göpel et al., 1994). It is unclear whether the Lu-Hf system in chondrites dates formation of their components (chondrules, CAIs, etc.), accretion, or some stage of metamorphism or postmetamorphic cooling. Eucrites, on the other hand, are metamorphosed igneous rocks with prolonged geological history, which might have spanned 100-150 m.y. after the beginning of the solar system formation (e.g., Tera et al., 1997). Despite uncertainties in meteorite ages, it is clear that the available meteorite $\mathrm{Lu}-\mathrm{Hf}$ data (shown as $\varepsilon{ }^{176} \mathrm{Hf}(\mathrm{T})$ values plotted against ${ }^{176} \mathrm{Lu} /{ }^{177} \mathrm{Hf}$ in Fig. 5) cannot be easily reconciled with the slow decay if ${ }^{176} \mathrm{Lu}$ deduced from terrestrial data. To make the chondrite Lu-Hf isochron of Bizzarro et al. (2003a) compatible with $\lambda^{176} \mathrm{Lu}$ determined by Scherer et al. (2001), it would be necessary to assume an unrealistic age of $4.85 \mathrm{Ga}$ for chondrites. Similarly the Blichert-Toft et al. (2002) data for basaltic eucrites would require an age of $4.77 \mathrm{Ga}$ for compatibility with terrestrial $\lambda^{176} \mathrm{Lu}$.

The slope of a meteorite Lu-Hf isochron can be affected by additional factors that are unique to extraterrestrial materials. Here we briefly review the possible causes of positive initial slope of meteorite Lu-Hf isochrons.

\subsubsection{Memory from early Lu/Hf fractionation}

The difference between "terrestrial" and "meteoritic" $\lambda^{176} \mathrm{Lu}$ translates into a minimum difference of $\sim 2 \varepsilon$-units over the range of chondritic Lu/Hf reported by Bizzarro et al. (2003a) and Patchett et al. (2004). If part of the nebula was strongly enriched in Lu compared to Hf, it could have accumulated radiogenic Hf, which was later absorbed by accreting chondrite 

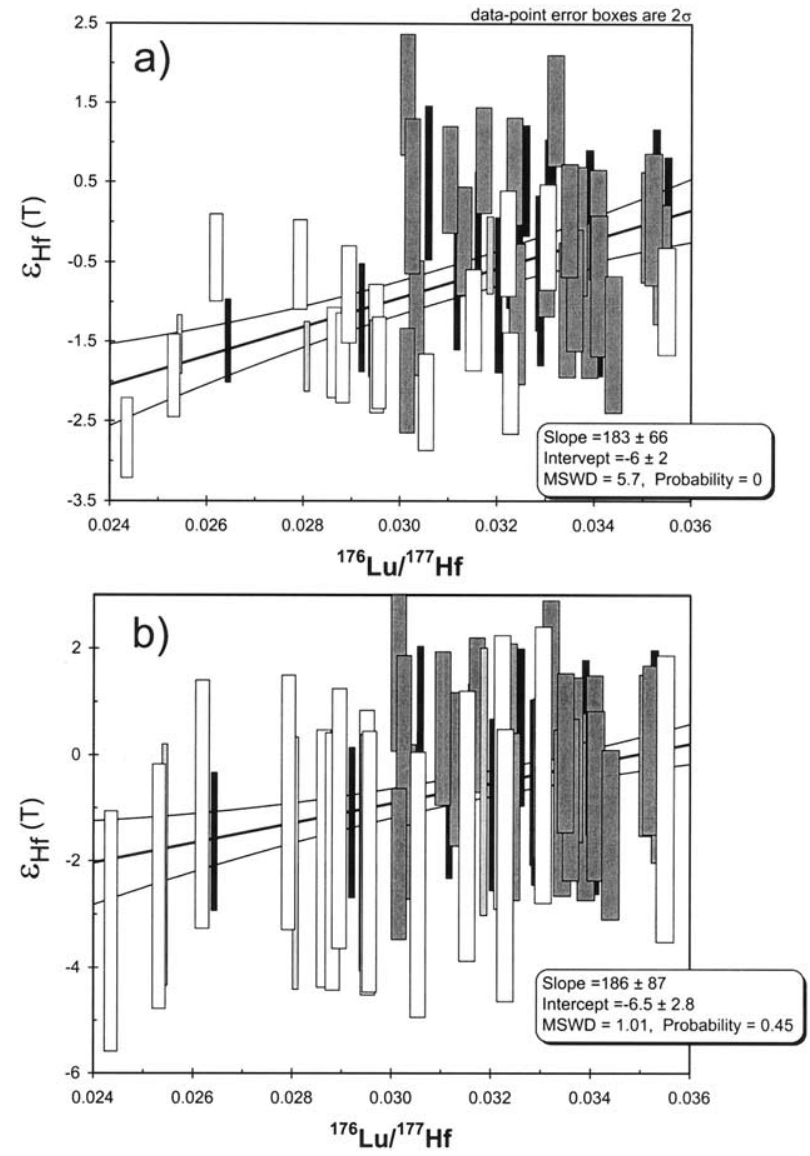

Fig. 5. Initial $\varepsilon^{176} \mathrm{Hf}$ (T) for chondrites (Bizzarro et al. (2003)black, Patchett et al. (2004) - gray) and noncumulate eucrites (Blichert-Toft et al. (2002) — white, Bizzarro et al. (2003a)—light gray), using $\lambda^{176} \mathrm{Lu}=1.865 \times 10^{-11}$ (Scherer et al., 2001). The data for cumulate eucrites are not included because their $\varepsilon^{176} \mathrm{Hf}(\mathrm{T})$ values have large errors. Errors of the $\varepsilon^{176} \mathrm{Hf}(\mathrm{T})$ values are propagated to include uncertainties in ${ }^{176} \mathrm{Lu} /{ }^{177} \mathrm{Hf},{ }^{176} \mathrm{Hf} /{ }^{177} \mathrm{Hf}$, and age. For data shown in the Figure $6 \mathrm{a}$, the age of all meteorites is assumed to be $4.56 \pm 0.01 \mathrm{Ga}$ (approximately the timing of accretion). For data shown in the Figure 5b, the conservative age estimates of $4.53 \pm 0.04 \mathrm{Ga}$ for chondrites and 4.464 $\pm 0.075 \mathrm{Ga}$ for eucrites, are used (see text for details).

parent bodies. If we assume the lifespan of this high-Lu/Hf material of $10 \mathrm{~m} . \mathrm{y}$. (a very generous estimate for the period between condensation of the first solids and accretion of chondrite parent bodies), then the minimum $\mathrm{Lu} / \mathrm{Hf}$ ratio required to produce a $2 \varepsilon$-unit increase in ${ }^{176} \mathrm{Hf} /{ }^{177} \mathrm{Hf}$ is $\sim 10$ times higher than the average chondritic value. A shorter (more realistic) accretion timescale, or a larger and more realistic delta $\varepsilon^{176} \mathrm{Hf}$ $(>2)$ would require even more extreme Lu/Hf fractionation. The mechanisms that could produce such high Lu/Hf enrichment, and then quantitatively remove Lu 5-10 m.y. later, are hard to envision. This suggestion is similar to the "pre-PAT Pb" hypothesis of Tera and Carlson (1999), and encounters similar difficulties.

\subsubsection{Existence of a hypothetical short-lived precursor of ${ }^{176} \mathrm{Lu}$ or ${ }^{176} \mathrm{Hf}$, not presently known to cosmochemists}

No known radioactive nuclide with mass 176 or 180 (we consider both $\beta$-decay and $\alpha$-decay), except ${ }^{176} \mathrm{Lu}$ itself, has a half-life longer than several hours (Audi et al., 1997) and may be suitable for this role.

\subsubsection{Nuclear reactions caused by cosmic rays}

The most common of these is capture of thermal neutrons produced by interaction of high-energy cosmic rays with planetary or meteoroid surfaces. Isotopic effects are rather large for certain nuclides with high thermal neutron cross sections, e.g., ${ }^{149} \mathrm{Sm},{ }^{155} \mathrm{Gd}$ and ${ }^{157} \mathrm{Gd}$, which have effective cross-sections (Lingenfelter et al., 1972) between $4 \times 10^{4}-2.4 \times 10^{5}$ barn (the effective cross sections vary with the composition of the rock). Thermal neutron fluences determined from Gd and Sm isotopic shifts in stony meteorites vary mostly between $10^{15}-10^{16} \mathrm{n} \times$ $\mathrm{cm}^{-2}$ (Bogard et al., 1995; Hidaka et al., 2000, and references therein), with corresponding shifts in $\varepsilon^{149} \mathrm{Sm}$ about -1 to -7 . Higher neutron fluxes and shifts in $\varepsilon^{149} \mathrm{Sm}$ up to -32 were found in aubrites (enstatite achondrites, Hidaka et al., 1999). Thermal neutron cross sections of the major Hf isotopes (176 to 180) and of ${ }^{175} \mathrm{Lu}$ are $10^{3}$ to $10^{4}$ times lower than that of ${ }^{149} \mathrm{Sm}$ (CRC Handbook, 2000), and therefore the neutron capture effects are expected to be negligible. ${ }^{176} \mathrm{Lu}$ has a higher neutron cross section, which is $\sim 20$ times lower than that of ${ }^{149} \mathrm{Sm}$, but the maximum anticipated effect of neutron capture on $\mathrm{Lu}$ isotopic composition, $\sim 1-2 \varepsilon$-units, would be insignificant.

\subsubsection{Preserved presolar nucleosynthetic heterogeneity}

${ }^{176} \mathrm{Lu}$ and ${ }^{176} \mathrm{Hf}$ are produced in stars by slow neutron capture (s-process) only (Klay et al., 1991; Lesko et al., 1991; Doll et al., 1999), whereas Hf isotopes from 177 to 180 are produced mainly in rapid neutron capture (r-process) with smaller contributions from s-process (e.g., Seeger et al., 1965). $S$-process and r-process occur in different stellar environments, and therefore nuclides produced preferentially by these processes resided in different mineral grains in a protosolar nebula. Incomplete mixing of sprocess and r-process components in chondrites may have caused local excesses of ${ }^{176} \mathrm{Lu}$ and ${ }^{176} \mathrm{Hf}$ in chondrites enriched in sprocess material. Incomplete mixing has been demonstrated for a number of elements, e.g., $\mathrm{Kr}, \mathrm{Xe}$ and $\mathrm{Ba}$, with the most pronounced s-process component enrichment observed in acid-insoluble fractions enriched in silicon carbide and diamond in some carbonaceous chondrites (Lewis et al., 1975; Ott and Begemann, 1990; Prombo et al., 1993). Much smaller, but still resolvable, variations are observed in $\mathrm{Ba}$ isotopic compositions in bulk carbonaceous chondrites Orgueil, Murchison and Allende (Harper et al., 1992; Hidaka et al., 2003). Orgueil and Allende appear to be enriched in the r-process component, and Murchison-in the s-process component relative to the average solar system $\mathrm{Ba}$. If incomplete mixing of s- and r-process components contributes to the Lu-Hf systematics of chondrites, then we can expect Murchison (an s-component enriched meteorite) to have higher ${ }^{176} \mathrm{Lu} /$ ${ }^{177} \mathrm{Hf}$ and ${ }^{176} \mathrm{Hf} /{ }^{177} \mathrm{Hf}$ ratios than more r-process enriched Allende. However, recent Lu-Hf studies of chondrites (Bizzarro et al., 2003a; Patchett et al., 2004) report higher ${ }^{176} \mathrm{Lu} /{ }^{177} \mathrm{Hf}$ and ${ }^{176} \mathrm{Hf} /{ }^{177} \mathrm{Hf}$ ratios in Allende than in Murchison, opposite to the expectation if nucleosynthetic heterogeneity caused an initial slope in chondrite $\mathrm{Lu}-\mathrm{Hf}$ isochrons. 


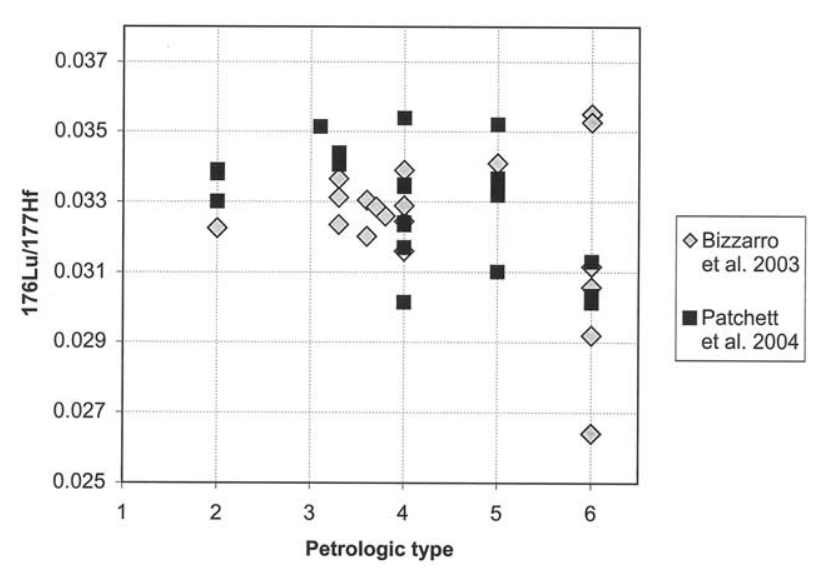

Fig. $6 .{ }^{176} \mathrm{Lu} /{ }^{177} \mathrm{Hf}$ ratios measured in recent studies of chondrites (Bizzarro et al., 2003a; Patchett et al., 2004) vs. petrologic types of chondrites. Petrologic subtypes of type 3 chondrites are from Grady (2000).

\subsubsection{Unsupported ${ }^{176} \mathrm{Hf}$, produced by decay of the ${ }^{176 m} \mathrm{Lu}$ nuclear isomer}

$S$-process produces the isomeric state ${ }^{176 m} \mathrm{Lu}$ along with ground state ${ }^{176} \mathrm{Lu}$. The ${ }^{176 \mathrm{~m}} \mathrm{Lu}$ decays to ${ }^{176} \mathrm{Hf}$ with a half-life of $3.66 \mathrm{~h}$. The ratio of production rates of ${ }^{176} \mathrm{Lu}$ and ${ }^{176 \mathrm{~m}} \mathrm{Lu}$ depends on the temperature at which s-process occurs (Beer et al., 1984; Klay et al., 1991; Lesko et al., 1991). If two or more stellar sources with different temperatures contributed s-process nuclides to the forming solar system, and the material was not completely mixed, then the initial ${ }^{176} \mathrm{Hf} /{ }^{177} \mathrm{Hf}$ ratio on the solar system may be heterogeneous. This possibility can be tested if another element containing two or more s-process isotopes with different temperature dependence of production rates is found. If these isotopes are free of other nucleosynthetic (e.g., r-process) or radiogenic contributions but their ratio in the solar system materials is variable, then the variations in the initial ${ }^{176} \mathrm{Hf} /{ }^{177} \mathrm{Hf}$ can be expected. We are not aware of such isotopic variations.

Possible mechanisms that may result in 'erroneous' meteorite Lu-Hf isochrons may be easier to decipher if we understood the cause of the spread in Lu-Hf ratios. For igneous meteorites, the spread is caused by magmatic differentiation and crystal fractionation. For chondrites, the cause of the spread is not obvious. However, the increase of the range of Lu/Hf variations in chondrites with petrologic type (i.e., with metamorphic temperature), shown in Figure 6, suggests that most of the spread is produced by metamorphic differentiation. This observation is easy to explain by growth of metamorphic minerals that strongly differentiate Lu from Hf, e.g., Ca phosphates. Magmatic and metamorphic controls of $\mathrm{Lu} / \mathrm{Hf}$ fractionation in meteorites are hard to reconcile with isotopic effects of variable cosmic ray exposure or nucleosynthetic heterogeneity. More straightforward evidence against the influence of the latter two factors on Lu-Hf systematics of meteorites can be provided by internal isochrons.

If future, more precise determinations of $\lambda^{176} \mathrm{Lu}$ confirm the currently observed discrepancy with the terrestrial Proterozoic to modern value, then it may be necessary to consider the case that $\lambda^{176} \mathrm{Lu}$ did indeed change between 4.5 and $2.8 \mathrm{Ga}(2.8 \mathrm{Ga}$ is the age of the oldest rock analyzed for terrestrial age comparisons, Scherer et al., 2003). This may be possible through time variation of fundamental constants. First suggested by Dirac (1938), cosmologies with changing fundamental "constants" occur in modern unifying physical theories (e.g., Damour, 2003). Changes of decay rates of ${ }^{187} \mathrm{Re},{ }^{40} \mathrm{~K}$ and ${ }^{87} \mathrm{Rb}$, as well as other isotopes, with the variation of fundamental couplings were modeled and compared to experimental evidence by Sisterna and Vucetich (1990) and Olive et al. (2002). Decays with smallest decay energy are the most sensitive to the variation in fundamental constants (Olive et al., 2002). The exceptionally small decay energy of ${ }^{187} \mathrm{Re}$ makes its decay rate much more sensitive to changing fundamental constants than the decay rates of ${ }^{40} \mathrm{~K},{ }^{87} \mathrm{Rb}$ and presumably ${ }^{176} \mathrm{Lu}$ (the latter has decay energy similar to that of ${ }^{40} \mathrm{~K}$, and $\sim 500$ times higher than $\left.{ }^{187} \mathrm{Re}\right)$. The decay constant of ${ }^{187} \mathrm{Re}$ determined from meteorite isochrons (i.e., integrated over last 4.56 b.y.) agrees within $3 \%$ error of the value determined by ingrowth experiments (present-day value) (Begemann et al., 2001; Olive et al., 2002, and references therein). Constancy of the ${ }^{187} \mathrm{Re}$ decay rate places strong constraints on the possible secular variability of decay rates of ${ }^{40} \mathrm{~K}$ and ${ }^{87} \mathrm{Rb}$. The same argument may be applied to ${ }^{176} \mathrm{Lu}$. A more certain answer can be obtained through modeling of the ${ }^{176} \mathrm{Lu}$ decay rate variations with changing fundamental couplings, which is beyond the scope of this paper.

\section{CONCLUSION}

A direct geochemical check for branched decay of ${ }^{176} \mathrm{Lu}$, critical analysis of age comparison studies using terrestrial rocks and meteorites, and evaluation of various possible complications of geochemical, nuclear, astrophysical and cosmological nature did not reveal the plausible cause of the ${ }^{176} \mathrm{Lu}$ dilemma. Resolving this problem will be a subject of future studies. The first and perhaps most important step to be taken is high-precision dating of meteorites with fast cooling and simple geological history, using internal isochrons and minerals that strongly fractionate Lu and $\mathrm{Hf}$ (e.g., phosphates).

Acknowledgments - This study started from a brief message from Paul Renne to the first author: "Is it quite certain that ${ }^{176} \mathrm{Lu}$ doesn't have a branched decay? That would be very interesting." Linda Cataldo helped with sample preparations for ICP-MS and TIMS analyses. The ICP-MS determinations would not have been possible without help from Nicole Bertrand and Will Doherty. The minerals from Fish Canyon Tuff were provided by Mike Villeneuve, separated from a sample collected by Paul Renne. The xenotime samples are provided by Richard Stern. This paper benefited from discussions of various aspects of the ${ }^{176} \mathrm{Lu}$ decay dilemma with Jon Patchett, Don Davis, Martin Bizzarro, Steve Galer, Paul Renne, Francis Albarede, Don Clayton and other colleagues, from internal review by Mike Villeneuve, and journal reviews by Don Davis, Jon Patchett, Eric Scherer and Janne Blichert-Toft. This is the GSC contribution number 2003291.

Associate editor: K. Kyser

\section{REFERENCES}

Amelin Y., Krot A. N., Hutcheon I. D., and Ulyanov A. A. (2002a) Lead isotopic ages of chondrules and calcium-aluminum-rich inclusions. Science 297, 1678-1683.

Anders E. and Grevesse N. (1989) Abundances of the elements: Meteoritic and solar. Geochim. Cosmochim. Acta 53, 197-214. 
Arnold J. R. (1954) Energy levels in Lu-176 and Hf-176. Phys. Rev. 93, 743-745.

Arnold J. R. and Sugihara T. (1953) The decay scheme of natural lutetium176. Phys. Rev. 90, 332.

Audi G., Bersillon O., Blachot J., and Wapstra A. H. (1997) The NUBASE evaluation of nuclear and decay properties. Nucl. Phys. A 624, 1-124.

Bachmann O., Dungan M. A., and Lipman P. W. (2002) The Fish Canyon magma body, San Juan volcanic field, Colorado: Rejuvenation and eruption of an upper-crustal batholith. J. Petrol. 43, $1469-1503$.

Beer H., Walter G., Macklin R. L., and Patchett P. J. (1984) Neutron capture cross sections and solar abundances of ${ }^{160,161} \mathrm{Dy},{ }^{170,171} \mathrm{Yb}$, ${ }^{175,176} \mathrm{Lu}$ and ${ }^{176,177} \mathrm{Hf}$ for s-process analysis of the radionuclide ${ }^{176}$ Lu. Phys. Rev. C 30, $464-478$.

Begemann F., et al. (2001) Call for an improved set of decay constants for geochronological use. Geochim. Cosmochim. Acta 65, 111-121.

Bizzarro M., Baker J. A., Haack H., Ulfbeck D., and Rosing M. (2003a) Early history of Earth's crust-mantle system inferred from hafnium isotopes in chondrites. Nature 421, 931-933.

Bizzarro M., Baker J., and Haack H. (2003b) Lu-Hf systematics of meteorites. EUG-2003. Geophys. Res. Abstr. 5, 09063.

Blichert-Toft J., Chauvel C., and Albarede F. (1997) Separation of Hf and $\mathrm{Lu}$ for high-precision isotope analysis of rock samples by magnetic sector multiple collector ICP-MS. Contrib. Mineral. Petrol. 127, 248-260.

Blichert-Toft J., Boyet M., Telouk P., and Albarede F. (2002) Sm-147Nd-143 and Lu-176-Hf-176 in eucrites and the differentiation of the HED parent body. Earth Planet. Sci. Lett. 204, 167-181.

Blichert-Toft J., Boyet M., and Albarède F. (2004) Further Lu-Hf and $\mathrm{Sm}-\mathrm{Nd}$ isotopic data on planetary materials and consequences for planetary differentiation. Lunar Planet. Sci. 35, 1226.

Bogard D. D., Nyquist L. E., Bansal B. M., Garrison D. H., Wiesmann H., Herzog G. F., Albrecht A. A., Vogt S., and Klein J. (1995) Neutron-capture ${ }^{36} \mathrm{Cl},{ }^{41} \mathrm{Ca},{ }^{36} \mathrm{Ar}$ and ${ }^{150} \mathrm{Sm}$ in large chondrites: Evidence for high fluences of thermalized neutrons. J. Geophys. Res. 100, 9401-9416.

Caro G., Bourdon B., Birck J.-L., and Moorbath S. (2003) ${ }^{146} \mathrm{Sm}-{ }^{142} \mathrm{Nd}$ evidence from Isua metamorphosed sediments for early differentiation of the Earth's mantle. Nature 423, 428-432.

Cumming G. L. and Richards J. R. (1975) Ore lead in a continuously changing earth. Earth Planet. Sci. Lett. 28, 155-171.

CRC Handbook of Chemistry and Physics. (2000) 3rd electronic ed. (equivalent to 81 st print edition). CRC Press.

Dalmasso J., Barcifunel G., and Ardisson G. J. (1992) Reinvestigation of the decay of the long-lived odd-odd Lu-176 nucleus. Appl. Radiat. Isotopes 43, 69-76.

Damour T. (2003) String theory, cosmology and varying constants. Astrophys. Space Sci. 283, 445-456.

Davis W. J. and Peterson T. (1998) New geochronological results for the Tavani area (55k), Eastern Kaminak Greenstone Belt, District of Keewatin. In Radiogenic and Isotopic Studies: Report 11. Current Research 98-2. Geological Survey of Canada. pp. 81-88.

Davis W. J., Lacroix S. Gariepy C., and Machado N. (2000) geochronology and radiogenic isotopic geochemistry of plutonic rocks from the central Abitibi subprovince: Significance to the internal subdivision of the Abitibi Belt. Can. Earth Sci. 37, 117-133.

Dirac P. A. M. (1938) A new basis for cosmology. Proc. R Soc. Lond. Ser. A 165, 199-208.

Dixon D., McNair A., and Curran S. C. (1954) The natural radioactivity of lutetium. Philos. Mag. 45, 683-694.

Doll C., Börner H. G., Jaag S., Käppeler F., and Andrejtscheff W. (1999) Lifetime measurement in ${ }^{176} \mathrm{Lu}$ and its astrophysical consequences. Phys. Rev. C 59, 492-499.

Evensen N. M., Hamilton P. J., and O'Nions R. K. (1978) Rare-earth abundances in chondritic meteorites. Geochim. Cosmochim. Acta 42, 1199-1212.

Flammersfeld A. (1947) K-Einfang Beim Naturlich Aktiven Cassiopeium. Zeitschr. Naturforschung 2 (2), 86-89.

Gehrke R. J., Casey C., and Murray R. K. (1990) Half-life of ${ }^{176} \mathrm{Lu}$. Phys. Rev. C 41, 2878-2882.

Glover R. N. and Watt D. E. (1957) A search for electron capture in ${ }^{176}$ Lu. Philos. Mag. 2, 699-702.
Göpel C., Manhès G., and Allègre C. J. (1994) U-Pb systematics of phosphates from equilibrated ordinary chondrites. Earth Planet. Sci. Lett. 121, 153-171.

Govindaraju K. (1994) 1994 compilation of working values and sample description for 383 geostandards. Geostand. Newslett. 18 (special issue), $158 \mathrm{pp}$.

Grady M. M. (2000) Catalogue of Meteorites. Cambridge University Press.

Grinyer G. F., Waddington J. C., Svensson C. E., Austin R. A. E., Ball G. C., Hackman G., O'Meara J. M., Osborne C., Sarazin F., Scraggs H. C., and Stöver H. D. H. (2003) Half-life of ${ }^{176}$ Lu. Phys. Rev. C 67, 014302.

Harper C. L., Wiesmann H., and Nyquist L. E. (1992) The search for ${ }^{135} \mathrm{Cs}$ in the early solar system: Very high precision measurements of barium isotopes in bulk Allende and refractory inclusions. $\mathrm{Me}$ teoritics $\mathbf{2 7}, 230-231$.

Hidaka H., Ebihara M., and Yoneda S. (1999) High fluences of neutrons determined from $\mathrm{Sm}$ and $\mathrm{Gd}$ isotopic compositions in aubrites. Earth Planet. Sci. Lett. 173, 41-51.

Hidaka H., Ebihara M., and Yoneda S. (2000) Isotopic study of neutron capture effects on Sm and Gd in chondrites. Earth Planet. Sci. Lett. $180,29-37$.

Hidaka H., Ohta Y., and Yoneda S. (2003) Nucleosynthetic components of the early solar system inferred from Ba isotopic compositions in carbonaceous chondrites. Earth Planet. Sci. Lett. 214, $455-466$.

Klay N., Käppeler F., Beer H., and Schatz G. (1991) Nuclear structure of ${ }^{176} \mathrm{Lu}$ and its astrophysical consequences. II. ${ }^{176} \mathrm{Lu}$, a thermometer for stellar helium burning. Phys. Rev. C 44, 2839-2849.

Lesko K. T., Norman E. B., Larimer R.-M., Sur B., and Beausang C. B. (1991) ${ }^{176} \mathrm{Lu}$ : An unreliable s-process cosmochronometer. Phys. Rev. C 44, 2850-2864.

Lewis R. S., Srinivasan B., and Anders E. (1975) Host phase of a strange xenon component in Allende. Science 190, 1251-1262.

Lingenfelter R. E., Canfield E. H., and Hampel V. E. (1972) The lunar neutron flux revisited. Earth Planet. Sci. Lett. 16, 355-369.

Ludwig K. R. (2001) Isoplot/Ex version 2.49, a geochronological toolkit for Microsoft Excel. Berkeley Geochronology Center Special Publication 1a.

Lugmair G. W. and Shukolyukov A. (1998) Early solar system timescales according to Mn-53-Cr-53 systematics. Geochim. Cosmochim. Acta 62, 2863-2886.

Makishima A. and Nakamura E. (1997) Suppression of matrix effects in ICP-MS by high power operation of ICP: Application to precise determination of $\mathrm{Rb}, \mathrm{Sr}, \mathrm{Y}, \mathrm{Ba}, \mathrm{REE}, \mathrm{Pb}, \mathrm{Th}$ and $\mathrm{U}$ at $\mathrm{ng} \mathrm{g}^{-1}$ levels in milligram silicate samples. Geostand. Newslett. 21, 307-319.

McCulloch M. T., DeLaeter J. R., and Rosman K. J. R. (1976) The isotopic composition and elemental abundance of lutetium in meteorites and terrestrial samples and the ${ }^{176} \mathrm{Lu}$ cosmochronometer. Earth Planet. Sci. Lett. 28, 308-322.

Nir-El Y. and Lavi N. (1998) Measurement of the half-life of ${ }^{176} \mathrm{Lu}$. Appl. Radiat. Isotopes 49, 1653-1655.

Nir-El Y. and Haquin G. (2003) Half-life of ${ }^{176}$ Lu. Phys. Rev. C 68, 067301.

Olive K. A., Pospelov M., Qian Y.-Z., Coc A., Cassé M., and Vangioni-Flam E. (2002) Constraints on the variations of the fundamental couplings. Phys. Rev. D 66, 045022.

Ott U. and Begemann F. (1990) Discovery of s-process barium in the Murchison meteorite. Astrophys. J. 353, L57-L60.

Parrish R. R., Roddick J. C., Loveridge W. D., and Sullivan R. W. (1987) Uranium-lead analytical techniques at the geochronology laboratory, Geological Survey of Canada. In Radiogenic Age and Isotopic Studies: Report 1, pp. 3-7. Paper 87(2). Geological Survey of Canada.

Patchett P. J. and Tatsumoto M. (1980) Lu-Hf total-tock isochron for the eucrite meteorites. Nature 288, 571-574.

Patchett P. J., Kouvo O., Hedge C. E., and Tatsumoto M. (1981) Evolution of continental-crust and mantle heterogeneity-Evidence from Hf isotopes. Contrib. Mineral. Petrol. 78, 279-297.

Patchett P. J., Vervoort J. D., and Söderlund U. (2004) Lu-Hf and $\mathrm{Sm}-\mathrm{Nd}$ isotopic systematics in chondrites and their constraints on the Lu-Hf properties of the earth. Earth Planet. Sci. Lett, 222, $29-41$. 
Prinzhofer A. and Allègre C. J. (1985) Residual peridotites and the mechanisms of partial melting. Earth Planet. Sci. Lett. 74, 251265.

Prombo C. A., Podosek F. A., Amari S., and Lewis R. S. (1993) $\mathrm{S}$-process $\mathrm{Ba}$ isotopic compositions in presolar $\mathrm{SiC}$ from the Murchison meteorite. Astrophys. J. 410, 393-399.

Robinson P., Townsend A. T., Yu Z., and Münker C. (1999) Determination of scandium, yttrium and rare earth elements in rocks by high resolution inductively coupled plasma mass spectrometry. Geostand. Newsl. 23, 31-46.

Roddick J. C. (1987) Generalized numerical error analysis with applications to geochronology and thermodynamics. Geochim. Cosmochim. Acta 51, 2129-2135.

Rudnick R. L. and Fountain D. M. (1995) Nature and composition of the continental-crust-A lower crustal perspective. Rev. Geophys. 33, 267-309.

Sato J., Ohoka Y., and Hirose T. (1983) The half-life of Lu-176. Radiochem. Radioanalyt. Lett. 58, 263-270.

Scherer E., Münker C., and Mezger K. (2001) Calibration of the lutetium-hafnium clock. Science 293, 683-687.

Scherer E., Mezger K., and Münker C. (2002) The ${ }^{176}$ Lu decay constant controversy (abstract V52B-1293). Presented at the AGU fall meeting.

Scherer E., Mezger K., and Münker C. (2003) The ${ }^{176}$ Lu decay constant discrepancy: Terrestrial samples vs. meteorites (abstract 5263). Presented at the 66th Annual Meteoritical Society Meeting.

Schmitz M. D. and Bowring S. A. (2001) U-Pb zircon and titanite systematics of the Fish Canyon Tuff: An assessment of highprecision $\mathrm{U}-\mathrm{Pb}$ geochronology and its application to young volcanic rocks. Geochim. Cosmochim. Acta 65, 2571-2587.

Seeger P. A., Fowler W. A., and Clayton D. D. (1965) Nucleosynthesis of heavy elements by neutron capture. Astrophys. J. 11 (Suppl.), $121-166$.

Sguigna A. P., Larabee A. J., and Waddington J. C. (1982) The half-life of ${ }^{176} \mathrm{Lu}$ by $\gamma-\gamma$ coincidence measurement. Can. J. Phys. 60, 361-364.
Sisterna P. and Vucetich H. (1990) Time variation of fundamental constants: Bounds from geophysical and astronomical data. Phys. Rev. D 41, 1034-1046.

Söderlund U., Patchett P. J., Vervoort J. D., and C. E. Isachsen. (2004) The ${ }^{176} \mathrm{Lu}$ decay constant determined by $\mathrm{Lu}-\mathrm{Hf}$ and $\mathrm{U}-\mathrm{Pb}$ isotope systematics of Precambrian mafic intrusions. Earth Planet. Sci. Lett. 219, 311-324.

Stern R. A. and Rayner N. (2003) Ages of several xenotime megacrysts by ID-TIMS: Potential reference materials for ion-microprobe U-Pb geochronology. Geological Survey of Canada, Current Research 2003-F1. Available at: http://www.nrcan.gc.ca/gsc/ bookstore/free/cr_2003/.

Taylor S. R. and McLennan S. M. (1995) The geochemical evolution of the continental-crust. Rev. Geophysics 33 (2), 241-265.

Tera F., Carlson R. W., and Boctor N. Z. (1997) Radiometric ages of basaltic achondrites and their relation to the early history of the solar system. Geochim. Cosmochim. Acta 61, 17131731.

Tera F. and Carlson R. W. (1999) Assessment of the Pb-Pb and U-Pb chronometry of the early solar system. Geochim. Cosmochim. Acta 63, 1877-1889.

Thirlwall M. F. (1991) Long-term reproducibility of multicollector Sr and $\mathrm{Nd}$ isotope ratio analysis. Chem. Geol. 94, 85-104.

Vance D. and Thirlwall M. (2002) An assessment of mass discrimination in MC-ICPMS using Nd isotopes. Chem. Geol. 185, 227-240.

\section{APPENDIX}

\section{SUPPLEMENTARY DATA}

Supplementary data associated with this article can be found, in the online version, at doi:10.1016/j.gca.2004.04.028. 